\title{
Effects of reciprocal peer feedback on EFL learners' communication strategy use and oral communication performance
}

\author{
Wei-Chieh Fang ${ }^{1}$, Farhad A. K. Cassim ${ }^{2}$ Chia-Ning Hsu ${ }^{3}$ and Nian-Shing Chen ${ }^{4 *}$
}

\author{
* Correspondence: nianshing@ \\ gmail.com \\ ${ }^{4}$ Department of Applied Foreign \\ Languages, National Yunlin \\ University of Science and \\ Technology, Yunlin, Taiwan \\ Full list of author information is \\ available at the end of the article
}

\begin{abstract}
While most studies focus on individual training of oral communication in English as a Foreign Language (EFL), this study took a social constructivist perspective in examining the effect of an interpersonal process, that is, peer feedback, on the development of oral communication performance and communication strategy use. A mobile application was developed to facilitate learners' engagement in discussion tasks, replay their conversation as well as carry out peer feedback. To examine the effect of mobile-assisted peer feedback, a quasi-experimental was conducted at a vocational university in Taiwan for five weeks. Forty EFL participants were assigned to an experimental group $(n=20)$, who received peer feedback on their oral communication performance and strategy use, and a control group $(n=20)$, who received no peer feedback on their oral communication ability and strategy use. The results show that the use of peer feedback enhanced students' oral communication performance but did not improve their communication strategy use. The findings suggest that with the support of mobile-based peer feedback, students were able to monitor their oral production and provide/receive corrective feedback that enhanced their overall communication performance. It was also found that the feedback provided by the students was not concrete enough to address the use of the target communication strategies. However, the peer feedback data show that students tended to provide varying communication strategies that were not taught in the study but were considered beneficial to their overall oral communication performance. Possible explanations for the findings and future directions are discussed in this paper.
\end{abstract}

Keywords: Mobile learning, Social constructivism learning, Peer feedback, Oral communication strategy, Oral communication performance

\section{Introduction}

The ability of EFL (English as a Foreign Language) learners to perform oral communication requires not only knowledge of the language, that is, vocabulary, grammar and pronunciation ability, but also the use of strategic knowledge, that is, another subset of language skills for fostering the conversation. This subset of skills can be termed communication strategies and its employment in conversational contexts means that any meaningful investigation of the learners' EFL speaking ability must also include an analysis of their employment of communication strategies.

(c) The Author(s). 2018 Open Access This article is distributed under the terms of the Creative Commons Attribution 4.0 International License (http://creativecommons.org/licenses/by/4.0/), which permits unrestricted use, distribution, and reproduction in any medium, provided you give appropriate credit to the original author(s) and the source, provide a link to the Creative Commons license, and indicate if changes were made. 
Strategic competence is defined as verbal and non-verbal communication strategies employed when communication breakdowns that may occur as result of either performance variables or insufficient competence need to be overcome (Canale \& Swain 1980). The commonly instructed oral communication strategies are circumlocution, appeal for help, asking for repetition, clarification request, confirmation request, self-repair, and guessing (Rabab'ah 2016). Several experts have described the interaction between oral communication strategy use and actual performance. It has been found that EFL learners can use the aforementioned communication strategies to compensate for their insufficient linguistic competence, which would otherwise lead to more disruptions in the conversation (Ellis 1984; Rabab'ah 2016). In other words, communication strategies are used to repair communication breakdowns, which in turn facilitates the conversational interaction between interlocutors. However, in addition to interpersonal benefits, these strategies also enhance the learners' oral communication proficiency, that is, they have particular intrapersonal benefits, because through negotiating, learners develop the specific abilities to modify their oral discourse, making it more intellectual and comprehensible, and they also learn how to seek for the content lacking in the other participant's spoken production (Long 1983; Rabab'ah 2016).

The importance of communication strategies in oral communication performance has meant that some researchers have focused on the variables facilitating its development. For example, studies have found that raising the learners' awareness of the communicative strategies improves communication strategy use and oral communication ability (Nakatani 2010; Rabab'ah 2016). The researchers conducting these studies, however, suffer from the drawback that they take a cognitive constructivist perspective, that is, they focus on how individuals cognitively develop the communication strategies through interaction with instruction and task. In doing so, they certainly provide an understanding of some of the intrapersonal variables involved but no insight into how interpersonal interaction develops strategic competence. Peer feedback, for example, is one kind of social interaction whose influence on the use of communication strategies is lacking in the EFL speaking literature (Nguyen 2013). Studies on the effect of peer feedback on oral communication ability and strategic competence, which would assume a social constructivism perspective, are also lacking in the literature because of inherent difficulties: oral production, unlike writing, is fleeting and hard to keep track of, making it difficult for learners to work on their oral production.

To address the above mentioned problem of keeping track of learners' oral production, researchers have long proposed that audio/video analysis of discourse should be integrated into courses to raise learners' meta-cognitive awareness (Faerch \& Kasper 1986). But audio or video recordings do not offer multiple functions as a digital platform would. With digital platforms, users can record their spoken production, provide feedback, and also instantly interact and exchange ideas with each other regarding provided feedback. As different functions are combined into one system, digital platforms save time and create more ease and comfort for the user. Thus, this study developed a digital platform, in the form of a mobile application, to explore the effects of peer feedback on EFL learners' strategic competence and oral communication performance.

Before proceeding to the next section, it should be emphasized that we conceptualize the interaction between the variables of our study in the same way that social constructivists do, rather than social cultural theorists. For social constructivism, learning is a 
social process in which social interactions such as pair work take place but it is also an individually constructed process. Providing peer feedback is one way to encourage social interactions, but peer feedback is also linked to Vygotsky's notion of the Zone of Proximal Development (ZPD), because learners individually construct and extend their knowledge and skills - their zone of proximal development-through socially mediated assistance (Nguyen 2013). Simply put, the outcomes of learning together and from each other are internalized by the learner. Thus, the aim of the current study was to examine the effect of peer feedback on the learning CS and oral communication performance from a social constructivism perspective.

\section{Literature review}

Oral communication strategies, hereafter referred to as CS, are the interactional strategies that interlocutors use to cope with communication breakdowns (Nakatani 2005). Several experimental studies on EFL training of CS have emphasized how conscious-raising can facilitate learners' communication strategies and oral communication ability (Nakatani 2005).

A fundamental study that informed our investigation was that of Rabab'ah (2016). Rabab'ah compared the effects of direct CS training in a communication class with a communication class that did not receive any CS instruction (Rabab'ah 2016). Learners went through four phases of instructional sequence: (1) consciousness-raising, (2) use of pre-fabricated patterns, (3) engagement in communicative activities, and (4) recording and evaluation as they worked with seven CS, namely circumlocution (paraphrase), appeal for help, asking for repetition, clarification request, confirmation request, self-repair, and guessing. Only three of these seven CS, e.g., appeal for help, confirmation checks, and clarification request, were adapted for use in this study for the reason that the study was performed on an existing class and had to respectfully cater to the requirements of the instructor, students, and course.

With Rabab'ah's (2016) study, the emphasis was on the use of prefabricated expressions as CS, such as "it is something you say when...," in different communicative activities. The results of the investigation showed that, over 14-week experimental period, learners who received CS training outperformed those who did not receive CS instruction in their speaking test scores and frequency of strategy use. Similarly, Nakatani (2005) raised students' awareness of the oral communication strategies by having students go through a five-phase instructional sequence: review, presentation, rehearsal, performance, and evaluation. The aim of the study was to explicitly train learners in the use of CS over the same task through repeated rehearsal and self-reflection. The results of the study concluded that conscious-raising through explicit training significantly improved learners' oral proficiency test scores and their CS use.

These studies reveal that instruction of CS leads to the development of strategic competence, which improves understanding, leads to agreement on meaning (e.g., negotiated meaning), and helps the speakers cope with communication breakdowns. Although combining a conscious-raising technique with instruction appears to be a promising approach, these studies view the learning of CS as an individual task, putting more emphasis on how an individual constructs the strategic knowledge by interaction with instruction. In other words, the research is focused on an intrapersonal level of 
analysis and fails to account for how interpersonal variables affect CS development and oral communication ability.

Essentially, there is a lack of studies that address the learning of CS from a social constructivist perspective (Nguyen 2013; Chew et al. 2018). The use of peer feedback, for example, is a practice that can involve language learning through social interaction (Min 2005; Wang et al. 2016). Theoretically, peer feedback is supported by the Vygotskian theory, which views learning as a socially constructed process (Vygotsky 1978). The mechanism is that peer feedback creates reciprocal opportunities for learners at varying levels of skills and competence to work together and provide each other with assistance to extend their competence (Min 2005). A large volume of research in EFL writing has adopted peer feedback to support learners' writing process and found improvement in text revision and writing quality (Lundstrom \& Baker 2009; Long 1983; Storch 2005; Yang 2011). However, to our best knowledge, there is very little research that uses peer feedback in EFL speaking. A study done by Huang (2010) is one of the few that examined the effect of group reflection on strategy use and oral language production. Although the objective of the study was to compare the effects of different modalities of reflection, the design of group spoken reflections involved peer review mechanisms to some extent. It was found that the group that practiced reflection as part of their team work had better CS use than the group that did not practice reflection. No difference was found in the oral production between the two groups.

Different from many studies whose emphasis is on an individual's learning of CS, our study engaged students in a reciprocal peer feedback process for learning the oral communication strategies and enhancing oral communication performance. Also, unlike most studies that compared CS instruction to non-CS instruction, our study included CS instruction for both conditions, but only one of them used peer feedback. In other words, previous research focused on the value of CS instruction, but our investigation moves the literature forward by focusing on the conditions that facilitate CS development. Finally, as urged by scholars, we used a mobile application to assist students in recording, replaying and exchanging ideas about their oral production so as to enhance meta-cognitive awareness. The mobile application was designed to implement peer review inside the classroom, and the use of peer feedback served as a mediational means to allow learners to observe their speaking processes as well as receive meta-cognitive support from their peers. Two research questions guided the study:

(1) Does implementing peer feedback through a mobile application enhance oral communication performance?

(2) Does implementing peer feedback through a mobile application enhance the use of oral communication strategies?

\section{Method}

To examine the effects of peer feedback on learners' oral communication performance and strategy use, a mobile application was designed. A quasi-experiment was conducted in a Presentation and Writing course at a vocational university over a period of five weeks. Since the course was discussion-based, the mobile application developed was used to engage students in the discussion tasks. Two classes of students, as a class, were randomly assigned into an experimental group and a control group, which were 
taught by the same instructor. Both groups received CS instruction and completed identical discussion tasks. Only the experimental group, however, went through a peer feedback process during the discussion tasks.

\section{Participants}

Forty-five undergraduate students participated in the 5-week experiment. Five students were deleted from the analysis because their pre- and posttests were incomplete, leaving forty valid participants, 20 for the experimental group and 20 for the control group. All of them were Mandarin speakers who majored in different fields and were registered for a general English course. They had an average score of $630(S D=89.30)$ on the TOEIC (Test of English for International Communication), which was considered an upper intermediate level in the English program. In this course, students were expected to develop both oral and written communication skills.

\section{Learning materials}

Learning materials for the two groups comprised a textbook titled English Presentation and Writing, an exercise sheet introducing 6 communication strategies and weekly handouts that offered real-life themes and discussion-based activities. First, the textbook was used in the first half of the semester for the purpose of developing basic oral and written communication skills. Second, the CS exercise sheet was used to present 6 interactional CS at the beginning of the experiment, namely Appeal for Help, Asking for Repetition, Confirmation Request, Clarification Request, Circumlocution, and Self-Repair (Rabab'ah 2016). The CS exercise sheet provided discussion activities where the students and the teacher worked together to come up with the prefabricated expressions when they encountered a communication problem. Third, the weekly handouts consisted of four themes, Skin Lightening, Real Life Problems, New Drugs Affecting Our Community, and Gender Equality, which were taught over the four weeks. Each theme presented a different communication skill aligned with the course goal as shown in Table 1 .

Table 1 Weekly themes and communication skills

\begin{tabular}{|c|c|}
\hline Themes & Communication skills/focus \\
\hline Skin lightening & $\begin{array}{l}\text { Expressing causation: } \\
\text { - Because of/Due to X, Y happens. } \\
\text { - X\{affects/influences/causes/produces/results in\} Y. }\end{array}$ \\
\hline Real life problems & $\begin{array}{l}\text { Stating solutions to problems: } \\
\text { - In order to solve this/these problem(s), one answer is ...; } \\
\text { a second/third/final answer is... } \\
\text { - In order to overcome this/these problem(s), one solution is...; } \\
\text { a thing we can do is... }\end{array}$ \\
\hline New drugs affecting our community & $\begin{array}{l}\text { Debating for position taken: } \\
\text { - Students take a side and argue whether a new drug should } \\
\text { be "legalized" or "banned." }\end{array}$ \\
\hline Gender Equality & $\begin{array}{l}\text { Debating with supporting evidence/examples: } \\
\text { - Students debate whether women are finally truly equal to } \\
\text { men and use ideas/examples given to create an argument for } \\
\text { a position taken. }\end{array}$ \\
\hline
\end{tabular}




\section{Peer feedback prompts and CS selection}

The aim of the current study was to train students to use CS and enhance their communication ability with peer feedback. Thus, the students were expected to use CS throughout the discussion each week, in which they were prompted with peer feedback questions to guide their communication. As stated in the previous section, the students were taught six CS. However, three most important oral CS, namely, confirmation request, clarification requests and circumlocution, were selected based on consultation with the course instructor and the guidelines proposed by Tarone (1983) and Dornyei and Scott (1997). These CS were considered the crucial ones that Taiwanese students needed to successfully participate in a classroom discussion at this level. Three corresponding prompting questions were designed by the authors and embedded in the mobile application to elicit peer feedback (see Table 2). The prompting questions asked students to provide CS-related examples used by their partner or to give new CS-related suggestions if their partners did not use any CS at all. In addition to the training of CS, the fourth prompting question, Which part do you think your partner needs to improve if he/she had a chance to have this conversation again?, was added to enhance overall oral communication.

\section{Oral production assessment}

An oral communication task was adapted from Nakatani's (2010) study to examine the two dependent variables of this study: Communication strategy use and oral communication performance. The task was modified to provide a more authentic context for Taiwanese university students (see Table 5 in Appendix). It served as both the pre- and posttests. In the task, each pair of students were given a hypothetical situation in which they carried out a role play to check in to a hotel. One student was given the role of a customer whereas the other took on the role of a hotel clerk. They were given 5 min to prepare the role play and were given 10 min to finish the simulated conversation task. The conversation was recorded and the task was completed via the mobile application.

To measure the use of communication strategy, the oral production was first transcribed and then classified by two trained research assistants. The transcription was

Table 2 Prompting questions and communication strategies and enhancers

\begin{tabular}{|c|c|c|}
\hline $\begin{array}{l}\text { Prompting questions } \\
\text { for peer feedback }\end{array}$ & $\begin{array}{l}\text { Communication strategies } \\
\text { and enhancers }\end{array}$ & Examples \\
\hline $\begin{array}{l}\text { Q1. Did your partner make } \\
\text { sure that you understand } \\
\text { what he/she wanted to say? }\end{array}$ & $\begin{array}{l}\text { Confirmation request } \\
\text { (Dornyei \& Scott 1997) }\end{array}$ & You mean he did not get my point? \\
\hline $\begin{array}{l}\text { Q2. Did your partner ask for } \\
\text { an explanation when he/she } \\
\text { didn't understand what you } \\
\text { had said? }\end{array}$ & $\begin{array}{l}\text { Clarification requests } \\
\text { (Dornyei \& Scott 1997) }\end{array}$ & What do you mean? \\
\hline $\begin{array}{l}\text { Q3. Did your partner try to use } \\
\text { other words or use another } \\
\text { description when you didn't } \\
\text { understand what he/she had said? }\end{array}$ & $\begin{array}{l}\text { Circumlocution } \\
\text { (Tarone 1983) }\end{array}$ & $\begin{array}{l}\text { It is something that we use to dry } \\
\text { our hands (Tissue). }\end{array}$ \\
\hline $\begin{array}{l}\text { Q4. Which part do you think your } \\
\text { partner needs to improve on if } \\
\text { he/she had a chance to have this } \\
\text { conversation again? }\end{array}$ & Communication enhancer & $\begin{array}{l}\text { Any oral example that the interlocutor } \\
\text { thinks functions as a discourse enhancer }\end{array}$ \\
\hline
\end{tabular}


based on: (1) students' active behavior in repairing and maintaining the interaction (Nakatani 2010), and (2) the three coding schemes, namely, confirmation request, clarification requests, and circumlocution taught in the course (Rabab'ah 2016). The inter-rater reliability based on kappa coefficients for confirmation request, clarification requests, and circumlocution were $0.85,1$, and 0.86 on the pretest, and $0.77,0.81$, and 0.76 on the posttest. To measure oral communication performance, the oral production of the students was rated by the two research assistants using an Oral Communication Assessment Scale developed for EFL learners (Nakatani 2010). The scale consisted of seven levels and focuses on the learner's fluency, ability to interact with the interlocutor, and flexibility in developing the conversation. The inter-rater reliability kappa coefficients for the oral performance scores were 0.88 on the pretest and 0.85 on the posttest. The content validity of the oral communication tasks was checked by two EFL instructors in the program.

\section{System design}

A mobile application was developed in Java programming language using the Android software development kit. The mobile application was compatible with wireless ASUS ZenPad 7.0 tablets. The server station was equipped with Windows 10, SQL Server 2016 Developer Edition, and an Internet connection that enabled real-time and interactive learning activities. To engage students in the classroom discussion and provide peer feedback, four phases of learning sequence were designed on a weekly basis: (1) Introduction of weekly discussion topics, (2) Discussion tasks, (3) Peer feedback on the conversation replay, and (4) Discussion/reflection on peer feedback. The following paragraph describes the features of the four phases.

In phase 1, the system introduces the topics of the week to the students as Fig. 1 shows. In phase 2, the system prompts the students to discuss the weekly topics in pairs and enter their conversation partners' responses, as Fig. 2 shows. During this phase, the students' conversation is automatically recorded for subsequent peer review.

In phase 3 , which is the peer review phase, the system prompts students to evaluate their partners' oral output in three steps as Fig. 3 shows. First, students are required to listen to the replay of their previous conversation. The replay of the conversation was mandatory but students could drag a bar to fast forward to the next step. Second, students are presented with the four prompting questions proposed in the present study. The first three prompting questions ask students to evaluate if their partners use the target CS by clicking yes or no. Third, students are prompted to enter the CS examples they hear if they click yes or provide their own CS examples if they click no. The fourth question asks students to provide suggestions to their partners for the purpose of improving their overall communication performance. The goal of this phase is to help the students evaluate their partners' use of the three target CS and their partner's overall communication performance.

In phase 4 , which is the discussion/reflection phase, as Fig. 4 shows, the system delivers the feedback to their respective conversation partners and prompts them to discuss it. Finally, the system asks all the students to reflect on their oral production and to rate their peers' feedback. Upon completion, the system shows the total star points awarded by the partners at the end of the weekly discussion task. Note that phase 3 


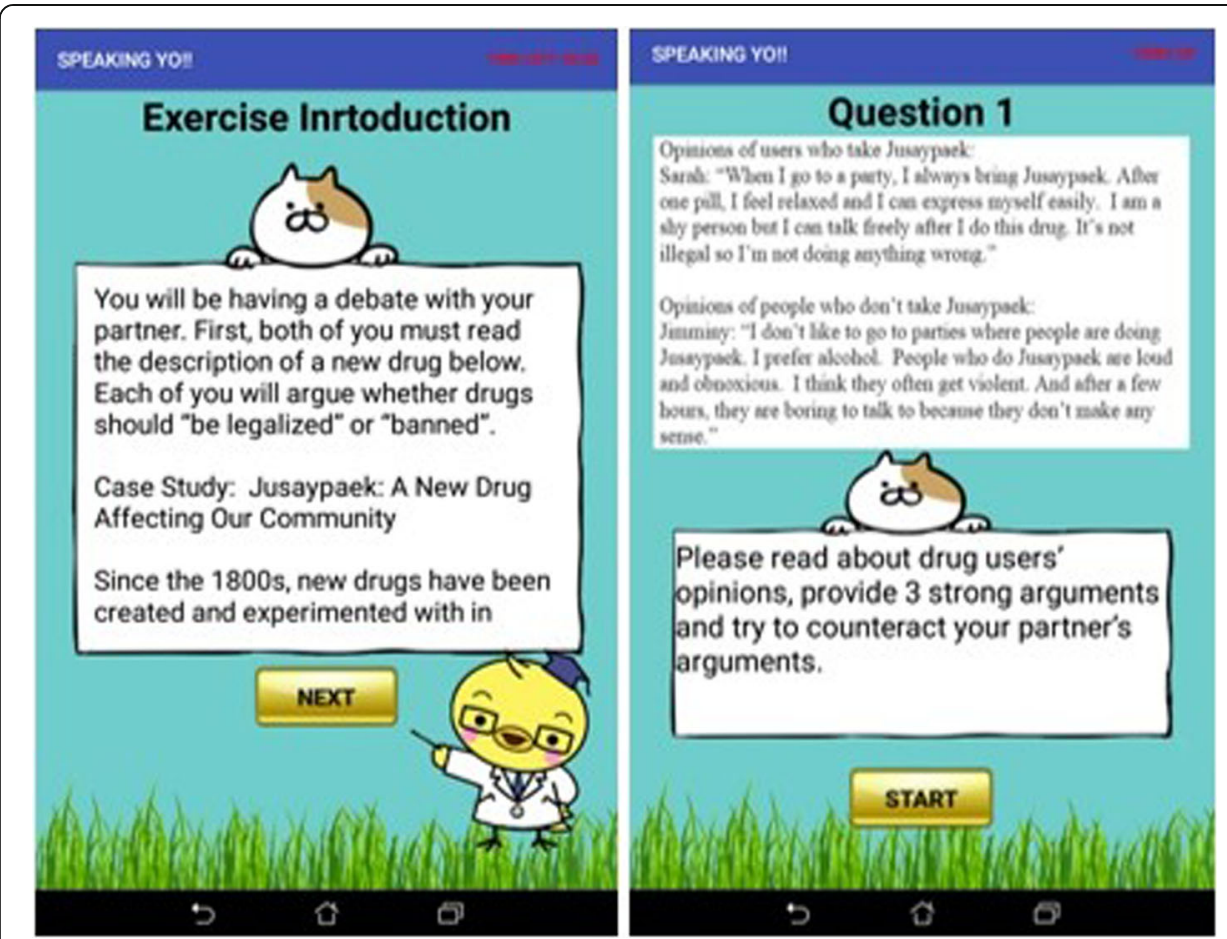

Fig. 1 Introduction of weekly discussion topics (Phase 1)

and 4 were designed to engage students in the peer review process. Thus, these two phases were not available for the control group.

\section{Procedure}

After the research team obtained students' consent on participation in the study, students received treatments according to the control and experimental groups assigned. Figure 5 shows the experimental procedure. In the first week, all students took a conversation simulation task as the pretest for $15 \mathrm{~min}$ on the application, in which they prepare a role-play for $5 \mathrm{~min}$ and engaged in the role-play task for $10 \mathrm{~min}$. Then, they were familiarized with the learning activities and the operation of the application. Following that, the students from both groups went through a brainstorming session to learn about the six CS for $30 \mathrm{~min}$. They were encouraged to use these CS throughout the experiment.

In week 2, 3, 4, and 5, students went through different phrases of learning activities depending on the group they were assigned to. Those in the experimental group were first introduced to the weekly topics in the first class for $50 \mathrm{~min}$ (phase 1). Then, in the second class, as Fig. 4 shows, they were randomly paired up to carry out discussion tasks for $30 \mathrm{~min}$ (phase 2). After the discussion tasks were done, they were asked to do peer review for $20 \mathrm{~min}$ (phase 3). Finally, they were asked to first discuss the feedback provided by the partners and then reflect on their own oral production. The control group did not go through phrase 3 and phase 4 as the peer review and discussion comprised the treatment of the experiment. The time for the discussion tasks was prolonged to $50 \mathrm{~min}$ for the control group so that the total learning time was held 


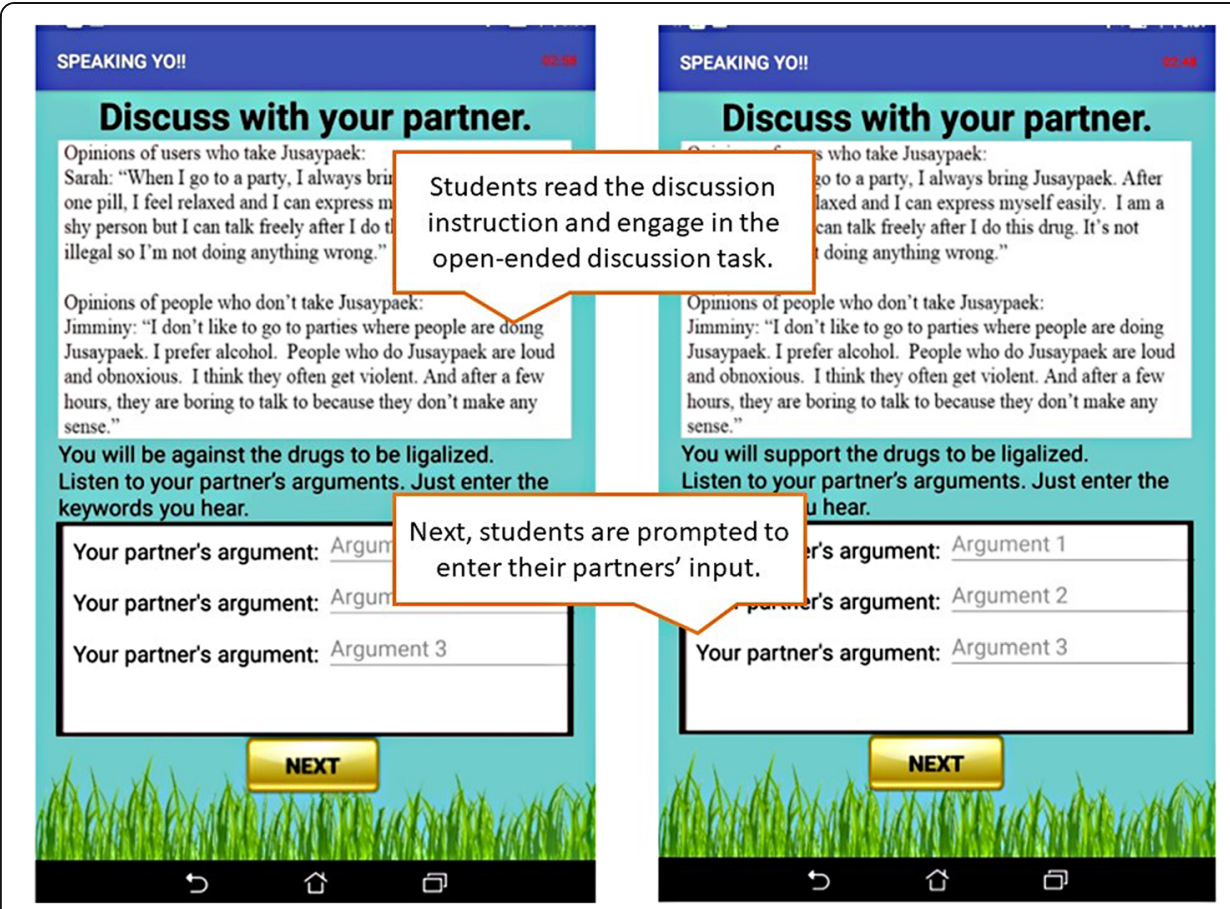

Fig. 2 Discussion tasks (Phase 2)

constant. Finally, an additional 20 min were added to week 5 in order to administer a post-test.

\section{Results and discussion}

\section{Oral communication performance}

The first research question is concerned with whether implementing peer feedback via the designed mobile application enhances oral communication performance. Since the study was not based on random assignment, an ANCOVA was performed using the
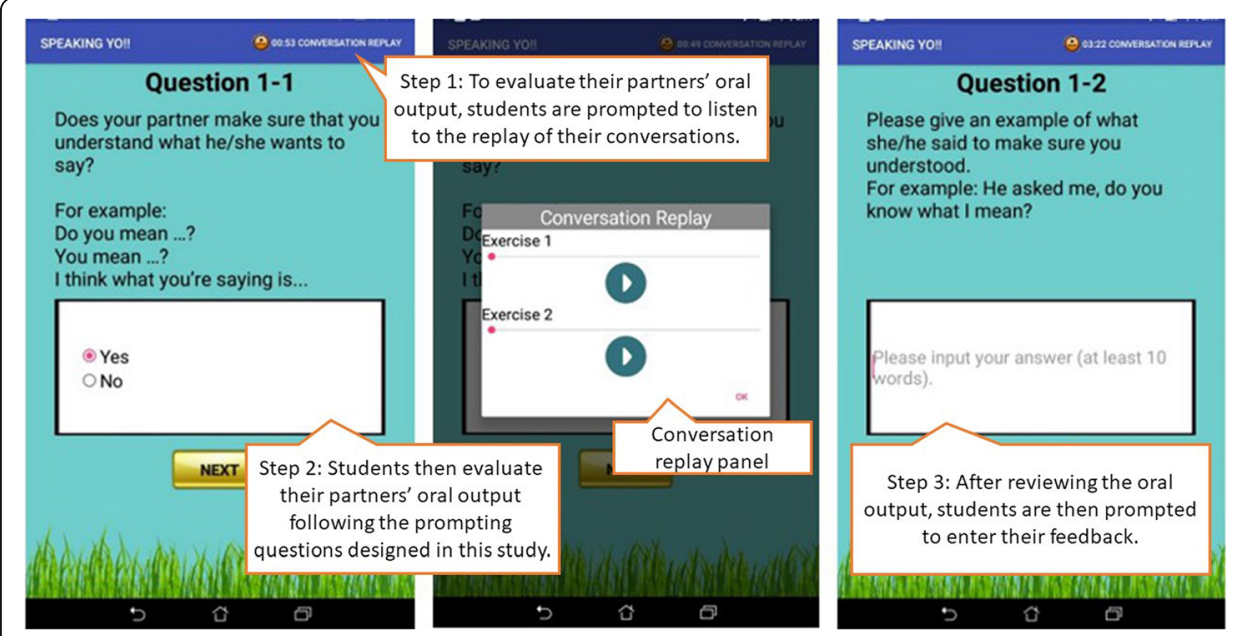

Fig. 3 Peer review on the oral output (Phase 3) 


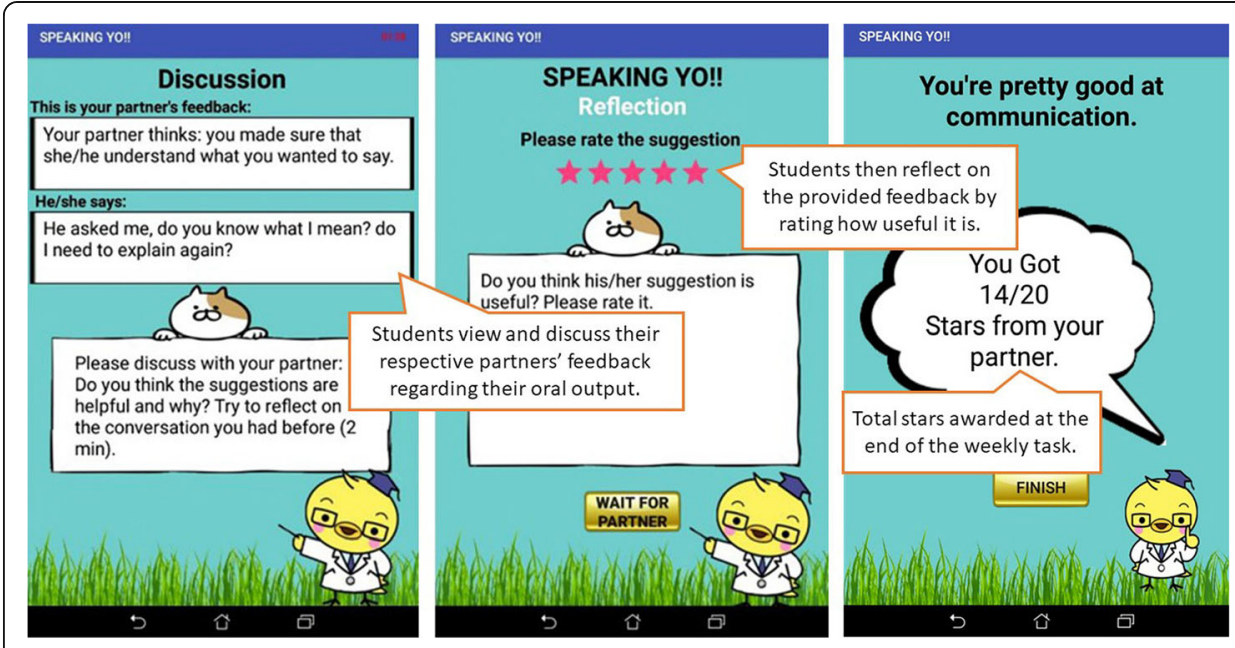

Fig. 4 Discussion/reflection on peer feedback (Phase 4)

oral scores on the pretest as covariate to control for the differences in oral communication ability prior to the intervention and the oral scores on the posttest as dependent variable. To ensure no interaction between the pretest scores and posttest scores, the assumption of homogeneity of regression slopes was tested and met. As Table 3 shows, after controlling for individual differences in communication ability, the experimental group $(M=4.62, S D=0.759)$ outperformed the control group $(M=3.98, S D=1.137)$ on the oral communication test, $F(1,37)=7.33, p=.010, \eta^{2}=.17$, with a medium effect size.

The results indicate that through peer feedback, students' oral communication performance was enhanced. The oral scores for the two groups fell into different levels of the oral communication scale. The oral scores for the control group fell into level 3 on the scale of 7 , suggesting that students' oral communication performance on the oral test was modest with frequent pauses and little flexibility in the dialogue according to

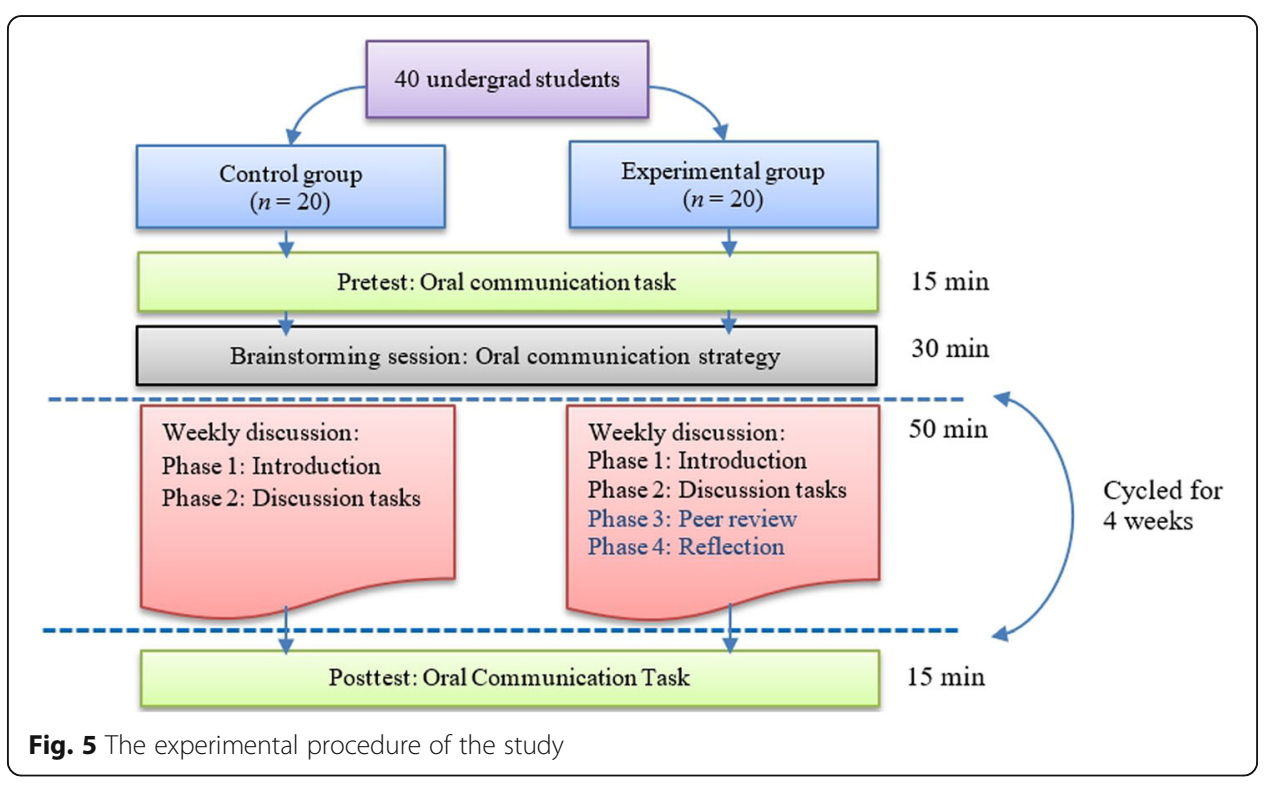


Table 3 Effects of treatment on oral communication performance

\begin{tabular}{lllllll}
\hline Group & $n$ & Mean & SD & $F$ & $p$ & $\eta^{2}$ \\
\hline Experimental & 20 & 4.62 & 0.17 & 7.33 & .010 & .17 \\
Control & 20 & 3.98 & 0.17 & & & \\
\hline
\end{tabular}

Note means were adjusted for the effect of the covariate

the assessment descriptors. By contrast, the oral scores for the experimental group fell into level 4. With their oral scores being significantly higher, the experimental group who received peer feedback made less pauses, showed more flexibility, and maintained the conversation in a more active way.

These findings are in line with Nakatani's (2005) and Rabab'ah's (2016) conclusion that increasing EFL students' awareness of their oral production and CS use leads to better communication performance. In their studies, they compared the effect of CS training to that of non-CS training. Our study, however, taught both groups CS but adopted peer feedback to examine its effect. Thus, we contributed a positive effect to the process of peer review. This result supports the prediction in previous research on peer feedback which indicates that students could accept their peers' suggestions and act upon them, leading students to make changes when they go onto their next assignment or learning tasks (Lai, 2016). Our system log revealed this learning pattern. It was found that students gave feedback that included identification of speech errors and corrective input, e.g., pointing out that "towel" should not be pronounced as "tower," which is essential for students to develop accuracy in communication.

Furthermore, from the social constructivism perspective, pairing students with different partners at varying levels of speaking competence and skills can help them become aware of the strengths and weaknesses or their oral communication performance (Min 2005; Wang et al. 2016; Lai 2016). Similarly, Interaction Hypothesis (Long 1983) argues that these interactional opportunities would allow learners to receive feedback on their language production and enable them to modify their speech so that learners can better focus on the development of their own target language.

\section{Communication strategies use}

The second research question is concerned with whether providing peer feedback via the designed mobile application enhances the use of the three target communication strategies. Three respective ANCOVAs, using CS pretest scores as covariate to control for individual differences in prior knowledge of CS, were performed on the number of the three target CS on the posttest. The results showed that there was no significant difference between the two groups in the use of Confirmation Request, $F(1,37)=.835$, $p=.367$, Clarification Request, $F(1,37)=1.212, p=.278$, and Circumlocution, $F(1,37)$ $=.054, p=.817$.

The results indicate that the use of peer feedback did not lead to more CS use. As Table 4 shows, it appears that the means of CS use in the current study, which ranged between 0.05 and 1.5, were relatively low when compared with the means reported by Nakatani (2010), which ranged between 1.14 and 4.82. Despite the low frequency in the use of all the target strategies, it appears that Taiwanese students, with an average of 75 to $80 \%$ of students, tended to use more of the confirmation request strategy than the 
Table 4 Means and standards deviations of different communication strategies used by the experimental group

\begin{tabular}{llllll}
\hline \multirow{2}{*}{$\begin{array}{l}\text { Communication } \\
\text { strategies }\end{array}$} & Experimental group & & \multicolumn{2}{l}{ Control group } & \\
\cline { 2 - 3 } & Posttest Means (SD) & $\%$ of Ss using CS & & Posttest Means (SD) & $\%$ of Ss using CS \\
\hline Confirmation request & $1.5(1.43)$ & $75 \%$ & & $1.15(0.99)$ & $80 \%$ \\
Clarification request & $0.05(0.22)$ & $5 \%$ & $0.15(0.37)$ & $15 \%$ \\
Circumlocution & $0.45(0.61)$ & $40 \%$ & $0.40(0.50)$ & $35 \%$ \\
\hline
\end{tabular}

other two strategies. Examples of the three types of CS as used by the students are as follows:

\section{Confirmation request strategy}

Hotel clerk (student A): There is no room [that] costs 20 dollars per night. Customer (student B): um.. you mean that there is no room that costs 20 dollars per night?

Clarification request strategy

Hotel clerk (student A): Can I use the traveler check for my payment?

Customer (student B): Travel what?

\section{Circumlocution}

Customer (student B): Can I put my package before we have done ...before we check in to the room.

A possible explanation for such low frequency in CS use is that the peer feedback provided might have brought learners' attention to their oral production, but may not have directly addressed the targeted CS. Our observation of the system log of weekly peer feedback revealed two major findings.

First, it was found that some learners provided non-linguistic/CS-related feedback, such as "He speaks common English. He does it very well. I think he can be better" for the clarification request. This type of feedback is referred to as rubber stamp advice (Min 2005; Tsui \& Ng 2000) because it does not directly address CS. This may be attributed to learners' insufficient knowledge and skills (Min 2005). Although social feedback as an approach may help learners to become aware of the target CS, it is possible that the ability to use CS might require more explicit training of certain expressions via memorization and focused practice. Nakatani's (2010) and Rabab'ah's (2016) studies found that mastery of prefabricated expressions can improve students' CS use. For example, when teaching the circumlocution strategy, Rabab'ah (2016) provided students a list of prefabricated phrases, e.g., "It is something you say when...," and had students practice describing an object using these phrases, e.g., "It is something you put in your car to make it go (gas)." This training might equip students with solid CS knowledge necessary for providing more concrete feedback. 
Another finding is that students tended to provide other communication strategies that were not taught in the current study and were conducive to the overall communication performance. Our system log indicated that although the feedback might not have directly addressed the target CS, a majority of students provided language feedback that improved mutual understating of the communication. Some students engaged in elaboration when explaining a difficult concept, such as "She tried to explain a difficult term by giving some examples." Numerous students also provided prosodic feedback, such as "He explained the complex sentences by slowing down the speaking speed," which made the oral output more comprehensible to partners. Some students also suggested the use of fillers, such as "He try to explain a term with expression like you know," which they felt could make the conversation flow better. The authors believe that these feedbacks served as great input for learners to reinforce varying communication strategies beyond what was taught as well as to modify their oral output over the cycles of peer feedback and discussion tasks. These findings might also account for the improved oral communication performance in the experimental group.

Our exploratory results indicate that reciprocal peer feedback is more effective in promoting overall oral performance than CS use. The process of peer review served as a potential learning activity for learners to help each other attend to their strengths or weaknesses in oral communication. This finding is in line with Vygotsky's notion of the ZPD, which proposes that learners can construct and extend their knowledge and skills through socially mediated assistance (Nguyen 2013). Most importantly, the mobile application played a facilitative role in making the implementation of peer feedback possible. It not only enabled the recording and reply of students' conversation while pacing the learning task for learners, but also made the peer review process a seamless and integral learning experience inside the classroom. This application can be particularly beneficial for a large language class in which interaction among students and teachers are rather difficult.

\section{Conclusions}

This study is among the few to examine the effect of reciprocal peer feedback on the use of communication strategies and oral communication performance from a social constructivism perspective. The design of the peer feedback embedded in a mobile application aimed to provide opportunities for leaners to learn from their peers, who would vary in their oral skills and competence, as well as opportunities to become aware of their use of communication strategies with the feedback they received. The results of our study show that the use of peer feedback enhanced students' overall oral communication performance over a learning period of 5 weeks. It did not improve the use of the three target CS, though. The learning of the target CS through peer feedback might require more instructional intervention. However, the data from the peer feedback process suggest that the mobile application could enable learners to monitor their oral production and to provide/receive corrective feedback and engage in varying communication strategies beyond the target ones, such as fillers, prosody and elaboration. The inputs provided by peers have a positive impact on learners' overall oral communication 
ability. Also, different from the prior studies that merely compared the effect of CS training to that of non CS instruction, the current study took the next step by examining the extent to which peer feedback can affect oral communication performance and CS use when both the control and the experimental groups receive CS instruction. Future research should continue examining how learners can provide more concrete and useful feedback when carrying out peer feedback. As the prior studies suggest, having students master prefabricated phrases are beneficial to the use of CS. Future studies can examine the effect of incorporating the training of prefabricated expressions into peer feedback process. It will also be beneficial to explore the effects of pairing learners with peers that are at a similar or different levels of language competence as a way to optimize the effect of peer feedback. Finally, since the learners used communication strategies beyond those that they were asked to work on, studies should examine the specific characteristics of learners and language use that makes this possible.

\section{Appendix}

Table $\mathbf{5}$ Oral Communication Task for Pretest and Posttest

Role A: You're a hotel clerk.

Please follow the instruction:

1. Read the scenario and task instruction for $5 \mathrm{~min}$.

2. Begin your role play with your partner for 10 min maximum.

3. Reminder: Act like you're a real hotel clerk and make sure that the options you provide meet guest's needs and follow the hotel's policies at the same time.

Task Scenario:

You are the hotel clerk at the Oasis Inn. You are helping a guest who is now checking in. The hotel has undergone many changes recently and the hotel clerical staff have been replaced; thus, there is no previous information about the customers. Due to hotel policy, you only accept credit card from foreigners. As this is a resort area, breakfast will be served relatively late at 8:00 am. The hotel has increased the room rates.

Rates: Single room $\$ 300$; Double room (no shower) $\$ 400$, Twin room (shower) $\$ 450$, Suite room $\$ 800$. All single rooms are booked for tonight.

Your task is to:

1. Help the guest check in

2. Respond to the guest's inquiries

3. Help book a new tour

Role B: Y ou're a guest, checking in at a hotel

Please follow the instruction:

1. Read the scenario and task instruction for $5 \mathrm{~min}$.

2. Begin your role play with your partner for 10 min maximum.

3. Reminder: Act like you're in a real trip and feel free to ask for discounts or reschedule to meet your travel plans.

Task Scenario:

You are on a trip in Florida, America. You are checking into a resort hotel. You booked a single room from Taiwan on hotel.com for two nights. You did not confirm the price of the room at that time but your travel guidebook has information about the prices, which states that your desired room costs 200 US dollars per night. Please use a traveler's check for payment and ask about the time of breakfast tomorrow morning. You intend to join a yacht tour, which your guidebook states will start at 8:00 a.m.

Your task is to:

1. Complete the check-in process

2. Confirm the inquiries you have

3. Book a new tour 


\section{Acknowledgements}

This research was supported by the National Science Council, Taiwan under project numbers MOST106-2511-S-110 -002 -MY3, MOST104-2511-S-110 -009 -MY3 and MOST104-2511-S-110 -007 -MY3. We thank Professor Hui-Chin Yeh at National Yunlin University of Science and Technology for her support.

\section{Funding}

This research was supported by the National Science Council, Taiwan under project numbers MOST106-2511-S-110 -002 -MY3, MOST104-2511-S-110 -009 -MY3 and MOST104-2511-S-110 -007 -MY3. We thank Professor Hui-Chin Yeh at National Yunlin University of Science and Technology for her support.

\section{Availability of data and materials}

The datasets used and/or analyzed during the current study are available from the corresponding author on reasonable request.

\section{Authors' contributions}

WCF and CNH designed the study, analyzed and interpreted the data. CNH developed the mobile application. WCF and FAKC were the major contributors in writing the manuscript. The whole process was supported and supervised by NSC. All authors read and approved the final manuscript.

\section{Authors' information}

Wei-Chieh Fang is a doctoral student in Applied Linguistics in Education, Washington University in St Louis. He holds a master's degree in Cognitive Psychology. His recent research explores the potential of using smartphones to facilitate communicative language teaching and the development of strategic competence in speaking. He has also worked on several projects exploring the effects of motion-sensing technology on language learning.

Farhad A. K. Cassim is a lecturer in the General Education Center at National Yunlin University of Science and Technology. He is focused on teaching EFL to non-English major students. His interests include studying the interactional patterns between learners that make extensive acquisition possible, big data, and practical assessments. Dr. Nian-Shing Chen is Feng-Tay Chair Professor in the Department of Applied Foreign Languages, National Yunlin University of Science and Technology. His current research interests include educational robotcs; online synchronous teaching \& learning; mobile \& ubiquitous learning; Natural user interface \& Game-based learning.

\section{Competing interests}

The authors declare that they have no competing interests.

\section{Publisher's Note}

Springer Nature remains neutral with regard to jurisdictional claims in published maps and institutional affiliations.

\section{Author details}

${ }^{1}$ Department of Education, Washington University in St Louis, Missouri, USA. ${ }^{2}$ General Education Center, National Yunlin University of Science and Technology, Yunlin, Taiwan. ${ }^{3}$ Department of Information Management, National Sun Yat-sen University, Kaohsiung, Taiwan. ${ }^{4}$ Department of Applied Foreign Languages, National Yunlin University of Science and Technology, Yunlin, Taiwan.

Received: 17 June 2018 Accepted: 13 August 2018

Published online: 22 August 2018

\section{References}

M. Canale, M. Swain, Theoretical bases of communicative approaches to second language teaching and testing. Appl. Linguis. 1(1), 1-47 (1980)

S.W. Chew, W.C. Fang, C.N. Hsu, N.S. Chen, in Challenges and Solutions in Smart Learning. Effects of reciprocal feedback on EFL learners' communication strategy use and oral communicative performance (Springer, Singapore, 2018), pp. 31-39

Z. Dornyei, M.L. Scott, Communication strategies in a second language: Definitions and taxonomies. Lang. Learn. 47, 173-210 (1997). https://doi.org/10.1111/0023-8333.51997005

R. Ellis, Communication strategies and the evaluation of communicative performance. ELT J. 38(1), 39-44 (1984). https://doi. org/10.1093/elt/38.1.39

C. Faerch, G. Kasper, in Learning, teaching and communication in the foreign language classroom. Strategic competence in foreign language teaching (1986), pp. 179-193

L.-S. Huang, Do different modalities of reflection matter? An exploration of adult second-language learners' reported strategy use and oral language production. System 38(2), 245-261 (2010) https://doi.org/10.1016/j.system.2010.03.005

C.Y. Lai, Training nursing students' communication skills with online video peer assessment. Comput. Educ. 97, 21-30 (2016)

M.H. Long, Native speaker/non-native speaker conversation and the negotiation of comprehensible input1. Appl. Linguis. 4(2), 126-141 (1983). https://doi.org/10.1093/applin/4.2.126

K. Lundstrom, W. Baker, To give is better than to receive: The benefits of peer review to the reviewer's own writing. J Second Lang Writing 18(1), 30-43 (2009) https://doi.org/10.1016/j.jslw.2008.06.002

H.-T. Min, Training students to become successful peer reviewers. System 33(2), 293-308 (2005). https://doi.org/10.1016/j. system.2004.11.003

Y. Nakatani, The effects of awareness-raising training on oral communication strategy use. Mod. Lang. J. 89(1), 76-91 (2005) https://doi.org/10.1111/j.0026-7902.2005.00266.x

Y. Nakatani, Identifying strategies that facilitate EFL learners' oral communication: A classroom study using multiple data collection procedures. Mod. Lang. J. 94(1), 116-136 (2010). https://doi.org/10.1111/j.1540-4781.2009.00987.x 
M.H. Nguyen, EFL students' reflections on peer scaffolding in making a collaborative oral presentation. English Language Teaching 6(4), 64-73 (2013)

G. Rabab'ah, The effect of communication strategy training on the development of EFL learners' strategic competence and oral communicative ability. J. Psycholinguist. Res. 45(3), 625-651 (2016). https://doi.org/10.1007/s10936-015-9365-3

N. Storch, Collaborative writing: Product, process, and students' reflections. J Second Lang Writing 14(3), 153-173 (2005) https://doi.org/10.1016/j.jslw.2005.05.002

E. Tarone, in Strategies in Interlanguage Communication, ed. by C. Faerch, G. Kasper. Some thoughts on the notion of communication strategy (Longman, London, UK, 1983), pp. 61-78

A.B.M. Tsui, M. Ng, Do secondary L2 writers benefit from peer comments? J Second Lang Writing 9(2), 147-170 (2000) https://doi.org/10.1016/S1060-3743(00)00022-9

L. Vygotsky, Interaction between learning and development. Readings on the development of children 23(3), 34-41 (1978)

Y. Wang, W.C. Fang, J. Han, N.S. Chen, Exploring the affordances of WeChat for facilitating teaching, social and cognitive presence in semi-synchronous language exchange Australas. J. Educ. Technol. 32(4) (2016)

Y.-F. Yang, A reciprocal peer review system to support college students' writing. Br. J. Educ. Technol. 42(4), 687-700 (2011). https://doi.org/10.1111/j.1467-8535.2010.01059.x

Submit your manuscript to a SpringerOpen ${ }^{\circ}$ journal and benefit from:

- Convenient online submission

- Rigorous peer review

- Open access: articles freely available online

- High visibility within the field

- Retaining the copyright to your article

Submit your next manuscript at $\boldsymbol{\nabla}$ springeropen.com 